\title{
Emerging from the Epicenter: Reflections on the COVID-19 Pandemic
}

\author{
Duy T. Dao, MD, MPH ${ }^{7}$ and Hong-An T. Nguyen, MD, MSC ${ }^{2,3}$
}

'Department of Surgery, NYU Grossman School of Medicine, New York, NY, USA; ${ }^{2}$ Division of Academic General Pediatrics, The Children's Hospital at Montefiore, Bronx, NY, USA; ${ }^{3}$ Department of Pediatrics, Albert Einstein College of Medicine, Bronx, NY, USA.

J Gen Intern Med 35(11):3376-7

DOI: $10.1007 / \mathrm{s} 11606-020-06112-6$

(C) Society of General Internal Medicine 2020

$\mathrm{O}$ ur heads were in the sand. As COVID-19 was spreading like wildfire across New York City in March, ${ }^{1}$ we started hearing about "redeployments." As a general surgery resident and general pediatrician, we believed no one would ask us to care for adults on floor and ICU units. We were wrong. Our personal lives and clinical practices have been completely upended. Along the way, we learned about the unpredictability of life and the remarkable generosity and ingenuity of humankind.

Duy: I started the trauma surgery rotation in midMarch. One morning, I examined a patient who had been admitted overnight after a fall. Other than gloves, I did not wear any other personal protective equipment; the patient exhibited no respiratory symptoms. A few days later, that same patient developed acute respiratory failure and was intubated. Our team compulsively self-monitored for symptoms while we waited for the test results. The COVID-19 test returned positive, and the patient ultimately succumbed to the disease. Soon, it became apparent that every patient who came through our trauma bay was a potential, if not likely, source of exposure. The feeling of uncertainty deepened among all of us.

Hong-An: I had trouble sleeping, and my anxiety levels skyrocketed as I left for work each morning. I was nervous about my one-hour subway commute to the Bronx, where I could not adequately maintain social distance on a crowded train. I became terrified of the rising xenophobia against Asian Americans. ${ }^{2,}{ }^{3}$ On multiple occasions, I raised the volume on my headphones and furtively avoided eye contact, drowning out racist comments such as "you can only catch the virus if you go to Chinatown."

Duy: Any sense of normalcy at work quickly disappeared. Soon, all elective surgeries were cancelled; even acute appendicitis and cholecystitis were prefer-

Received May 18, 2020

Revised July 1, 2020

Accepted August 4, 2020

Published online August 31, 2020 entially treated with antibiotics. To avoid exposure, residents took weekly turns between staffing the hospital and staying home as backup for emergent operations. This was a devastating blow to my training. For the next two weeks, I spent most days incessantly checking my phone or the electronic medical record for surgical emergencies that never happened. As the disruption wore on, restlessness and frustration also started to build up.

Hong-An: Parents got nervous about taking their children outside, including going to clinic. We agonized - how do we adequately care for our vulnerable families if they are afraid to come to one of their safe spaces? In a matter of days, we shifted to telephone visits, and started video visits shortly after. Often, after addressing the initial ailment, these calls shifted to managing the parents' anxiety. Some worried about buying food, formula, and diapers. Others were essential workers who recounted their decontamination routines, asking me if these were adequate to prevent them from bringing the virus home. I did what pediatricians often do: reassure. We offered each other words of encouragement, expressed through gentle smiles on our pixelated faces.

Duy: Staying home felt unfair when my fellow residents in internal medicine, emergency medicine, and anesthesia were being battered on the front lines. It almost felt like a relief when I redeployed to a COVID-19 ICU in early April. The scenes were grisly. In a unit of thirty patients, half were cannulated to ECMO and most had undergone one of several experimental treatments. As a surgical trainee, I always push myself to be prepared for and know everything I can about the day's scheduled operations. However, with rapidly changing guidelines and no FDA-approved treatments, nothing could prepare me for COVID-19. We were all learning on the fly, and I had to get used to it.

Hong-An: In early April, I redeployed to the pediatric inpatient units. I felt glad to be able to help in a more tangible way, but I was wary about being out of my depth. One of our floors became an adult COVID-19 unit. ${ }^{4}$ Pediatricians were asked to care for patients in their $50 \mathrm{~s}, 60 \mathrm{~s}$, even $70 \mathrm{~s}$, with internal medicine hospitalists as consultants. For most of us, the last time we cared for patients in this age range was during medical school. It was already challenging to manage 
a novel illness in young adults who required nonrebreather masks and high flow nasal cannulae on the floors. How were we supposed to feel comfortable caring for older adults with chronic illnesses?

All of a sudden, our redeployments to COVID-19 units came to a screeching halt. We both tested positive for SARS-CoV-2. Recuperating from this illness together allowed us time to reflect on the overwhelming sense of isolation this pandemic has wrought into every aspect of our lives. During our redeployments, we were separated from our colleagues and our clinical homes. Our patients were unable to be comforted by the touch of their loved ones. For families of critically ill patients, waiting by their phones for updates was an agonizing daily practice. Many patients died alone. Tragically, some were only allowed visitors before withdrawal of medical support.

However, we remain comforted by the silver lining that has emerged from this trying time: a remarkable display of camaraderie and perseverance from the medical community. Medical providers, irrespective of specialties or credentials, came together with a single goal. Sometimes, it takes a major jolt like a pandemic to prove what we are capable of. Our institutions swiftly adapted new patient care practices during the surge, and some are here to stay. Higher acuity postoperative patients are now managed on the floors due to increased training among nursing staff. Pediatric rashes, chronic care follow-ups, and symptom checks for select post-operative patients can be addressed via telemedicine.

We are settling into a mask-wearing, socially distanced new "normal." But we are still nervous. Our elderly parents and relatives live in states where COVID-19 cases are rising. ${ }^{5}$ How long will it take until we can safely visit them again? It pains us to see our colleagues around the country buckle against yet another rising tide of patients. We have suffered and learned so much. It's not yet time to take our feet off the gas.

Acknowledgments: We thank our families and friends across the USA and our colleagues at NYU Langone Health and The Children's Hospital at Montefiore for their unwavering support during these challenging times.

Corresponding Author: Hong-An T. Nguyen, MD, MSc; Division of Academic General Pediatrics, The Children's Hospital at Montefiore, Bronx, NY, USA (e-mail: honnguyen@montefiore.org).

\section{REFERENCES}

1. New York State Department of Health. COVID-19 Tracker. Published 2019 https://covid19tracker.health.ny.gov/views/NYS-COVID19-Tracker/ NYSDOHCOVID-19Tracker-Map. Accessed May 3, 2020.

2. Escobar N. When Xenophobia Spreads Like A Virus. NPR. https://www. npr.org/2020/03/02/811363404/when-xenophobia-spreads-like-a-virus. Published Mar 4, 2020.

3. Rogers K, Jakes L, Swanson A. Trump Defends Using "Chinese Virus" Label, Ignoring Growing Criticism. The New York Times. https://www. nytimes.com/2020/03/18/us/politics/china-virus.html. Published Mar $18,2020$.

4. Philips K, Uong A, Buckenmyer T, et al. Rapid Implementation of an Adult Coronavirus Disease 2019 Unit in a Children's Hospital. J Pediatr 2020;222:22-27. https://doi.org/10.1016/j.jpeds.2020.04.060.

5. Coronavirus in the U.S.: Latest Map and Case Count. The New York Times. Published 2020. https://www.nytimes.com/interactive/2020/us/coronavirus-us-cases.html. Accessed Jul 1, 2020.

Publisher's Note Springer Nature remains neutral with regard to jurisdictional claims in published maps and institutional affiliations. 